\title{
Влияние тиотропия бромида на морфофункциональные свойства нейтрофилов и макрофагов бронхиального дерева при хронической обструктивной болезни легких стабильного течения
}

\author{
1 - ГОУ ВПО "Сибирский государственный медицинский университет Росздрава", кафедра госпитальной терапии с курсом физической реабилитации и \\ спортивной медищины: 634050, Томск, Московский тр., 2; \\ 2 - ФГОУ ВПО "Военно-медицинский институт МО РФ", цитологическая лаборатория: 634041, Томск, пр. Кирова, 49
}

\section{S.V.Fedosenko, G.E.Chernogoryuk, E.P.Roslyakova \\ Influence of tiotropium bromide on morphofunctional properties of neutrophils and macrophages in the airways of patients with stable chronic obstructive lung disease}

\begin{abstract}
Summary
The aim of this study was to investigate the influence of tiotropium bromide on morphofunctional parameters of neutrophils and macrophages in the airways of patients with stable COPD. This stratified prospective open comparative controlled study involved 21 patients with GOLD stage II COPD (the group 1) and 30 patients with stage III-IV COPD (the group 2) who had not received any maintenance therapy before the study and 27 patients with stage III-IV COPD treated with a fixed combination fluticasone propionate / salmeterol (the group 3). All the patients were given tiotropium bromide for 3 months. Neutrophil and macrophage number in the induced sputum, cell size, areas of cytoplasm and the nucleus, concentration of myeloperoxidase and cationic protein in the neutrophil cytoplasm were measured before and after the treatment course.

Results. After 3 months of the therapy, neutrophils and macrophages in the induced sputum of all the patients were characterized by larger size, increased cytoplasm area, decreased ratio of nucleus and cytoplasm, accumulation of myeloperoxidase and cationic protein in the cytoplasm of neutrophils. In conclusion, 3-month course of tiotropium could improve qualitative parameters of the key effector cells. These changes were observed in all groups of patients irrespective of previous treatment of COPD.
\end{abstract}

Key words: chronic obstructive lung disease, neutrophiles, macrophages, myeloperoxidase, cationic protein.

\section{Резюме}

Целью стратифицированного открытого контролируемого проспективного сравнительного исследования было определение влияния тиотропия бромида на морфофункциональные свойства нейтрофилов и макрофагов бронхиального региона при хронической обструктивной болезни легких. Были обследованы 21 пациент с ХОБЛ II стадии без предшествующей терапии (1-я группа), 30 больных ХОБЛ III-IV стадии без предшествующей терапии (2-я группа) и 27 пациентов с ХОБЛ III-IV стадии, применявшие ранее фиксированную комбинацию флутиказона пропионат / салметерол (3-я группа). Пациентам был назначена 3-месячная терапия тиотропия бромидом. До и после курса лечения в индуцированной мокроте определяли содержание нейтрофилов и макрофагов, размер клеток, площадь цитоплазмы и ядра, содержание миелопероксидазы и катионного протеина в нейтрофилах. Через 3 мес. терапии тиотропия бромидом в индуцированной мокроте всех групп пациентов нейтрофилы и макрофаги характеризовались более крупным размером, отмечалось увеличение плошади цитоплазмы в клетках и снижение ядерно-цитоплазматического отношения. Также наблюдалось накопление миелопероксидазы и катионного протеина в цитоплазме нейтрофилов. Применение тиотропия бромида в течение 3 мес. позволило сушественно улучшить качественные характеристики ключевых эффекторных клеток. Выявленные изменения наблюдались во всех группах больных независимо от предшествующего режима лечения ХОБЛ.

Ключевые слова: хроническая обструктивная болезнь легких, нейтрофилы, макрофаги, миелопероксидаза, катионный протеин.

Известно, что тиотропия бромид воздействует на основные патофизиологические вентиляционные механизмы: обладает длительным бронхорасширяющим действием, уменьшает гиперинфляцию. Вместе с тем есть все основания полагать, что постоянная терапия больных ХОБЛ тиотропия бромидом сопровождается уменьшением воспаления в бронхах. Механизмы этого эффекта раскрыты не полностью.

В сложной иерархии клеточных отношений при хронической обструктивной болезни легких (ХОБЛ), ключевым элементом является нейтрофил [1]. Зрелый нейтрофил выбрасывается в циркуляцию, где имеет короткий период жизни, на протяжении которого, он либо привлекается в регион воспаления, либо стареет и устраняется [2]. Известно, что у больных ХОБЛ размер нейтрофилов в индуцированной мокроте меньше, чем у здоровых лиц [3]. Процесс миграции связан с активацией нейтрофилов, проявляющейся мобилизацией азурофильных гранул и их экзоцитозу с выделением энзимного содержимого [4]. Это подтверждается обнаружением в супернатанте мокроты повышенной концентрации миелопероксидазы (МПО) и катионных протеинов [5]. МПО - один из основных биомаркеров, отражающих активность нейтрофильного воспаления [6]. В целом содержание МПО в нейтрофилах индуцированной мокроты у пациентов с ХОБЛ выше, чем у здоровых некурящих добровольцев, что отражает высокий воспалительный потенциал фагоцитарной 
системы. Однако по мере прогрессирования болезни активность МПО в них снижается, одновременно с этим наблюдается увеличение внеклеточно расположенного фермента [7]. Обилие опустошенных мелких нейтрофилов, практически не содержащих миелопероксидазы и катионного протеина, - типичная картина в индуцированной мокроте при тяжелом / очень тяжелом течении ХОБЛ. Последующая судьба таких клеток - гибель путем апоптоза или некроза. Апоптозные клетки редко обнаруживаются в здоровых легких человека [8]. Их количество возрастает при хронических воспалительных болезнях легких, в большей степени - по причине уменьшения удаления клеток (эффероцитоза) [9].

При ХОБЛ эффероцитоз подвергшихся апоптозу нейтрофилов является дефектным [10]. В норме для резидентных макрофагов легких с ультраструктурными признаками выраженного фагоцитоза характерны наиболее крупные размеры и низкое ядерноцитоплазматическое отношение. Однако именно этот пул фагоцитов страдает при ХОБЛ, несмотря на то, что в целом количество макрофагов в индуцированной мокроте и лаважной жидкости у больных увеличивается. Клиническая группа под руководством M.Frankenberger идентифицировала особую популяцию макрофагов индуцированной мокроты больных ХОБЛ, обладающих меньшими размерами [11]. У здоровых эта популяция "малых макрофагов" составляет только около $7 \%$ от всех макрофагов, в то время как у больных ХОБЛ она может повышаться до $90 \%$ в период острых эпизодов. В ответ на персистентное легочное воспаление на смену зрелым макрофагам приходят рекрутированные из периферической крови моноциты. Но их фагоцитарная активность оказывается значительно более низкой, по сравнению с резидентными макрофагами [11]. Таким образом, процессы апоптоза нейтрофилов и своевременное удаление апоптозных клеток макрофагами определяют сохранность легочной структуры.

Целью исследования было определение влияния тиотропия бромида на морфофункциональные свойства нейтрофилов и макрофагов бронхиального дерева при ХОБЛ.

\section{Материалы и методы}

Исследование проводилось в дизайне стратифицированного открытого контролируемого проспективного сравнительного исследования с курсом терапии тиотропия бромидом длительностью 3 мес. в параллельных группах.

Методом случайной выборки в исследование были включены 78 пациентов обоего пола (15 женщин и 63 мужчины), страдающих стабильной ХОБЛ II-IV стадии. Из них 21 человек с ХОБЛ II стадии, ранее не получавшие поддерживающей терапии (1-я группа), 30 больных ХОБЛ III-IV стадии, также ранее не получавшие поддерживающей терапии (2-я группа), и 27 пациентов с ХОБЛ III-IV стадии, получавшие ранее фиксированную комбинацию флутиказона пропионат / салметерол на протяже- нии $\geq 6$ мес. (3-я группа). Пациентам всех групп назначался 3-месячный курс тиотропия бромида в стандартной дозе - 18 мкг ингаляционно 1 раз в сутки. Пациентам 3-й группы тиотропия бромид был назначен в дополнение к комбинации флутиказона пропионат / салметерол.

У всех пациентов до и после курса лечения тиотропия бромидом по стандартной методике проводился забор индуцированной мокроты для приготовления мазков. Окраска мазков на МПО осуществлялась бензидином по методу Грэхема-Кнолля. Для определения катионного протеина мазки окрашивались прочным зеленым по модифицированному методу B.E.Пигаревского. Определение содержания цитоферментов, измерение размеров нейтрофилов и макрофагов, площади цитоплазмы и ядра в них проводилось методом компьютерной цитоморфометрии в программе Adobe Photoshop. В рамках цитохимического исследования нейтрофилов индуцированной мокроты содержание миелопероксидазы (МПО) и катионного протеина (КП) определялось дважды: до и после терапии тиотропия бромидом. Содержание МПО и КП в клетке оценивалось по результатам цитохимической реакции исследуемого вещества с реагентами в единицах оптической плотности бо́льшему значению показателя соответствовала меньшая концентрация фермента.

Статистическая обработка данных проводилась с использованием пакета программ Statistica 6.0 (StatSoft, USA). Для сравнения групп показателей использовались непараметрические методы. Пороговый уровень статистической значимости принимался при значении критерия $p<0,05$.

\section{Результаты и обсуждение}

Результатом лечения тиотропия бромидом были морфологические изменения нейтрофилов бронхиального дерева. После 3-месячной терапии тиотропия бромидом произошло увеличение средних размеров нейтрофилов индуцированной мокроты у больных ХОБЛ II стадии, ранее не получавших поддерживающей терапии, и в группе больных с III-IV стадией ХОБЛ, которым тиотропия бромид был добавлен к ранее начатому лечению комбинацией флутиказона пропионат / салметерол (табл. 1).

Возрастание средних размеров нейтрофилов произошло вследствие увеличения площади цитоплазмы. Различные условия терапии тиотропия бромидом, такие как степень тяжести болезни, предшествующая терапия флутиказона пропионатом / салметеролом и последующая сочетанная терапия тиотропия бромидом + флутиказона пропионат / салметерол не влияли на направленность изменений морфометрических показателей нейтрофилов - во всех группах в результате лечения тиотропия бромидом произошло увеличение средних размеров цитоплазмы этих клеток и, соответственно, уменьшение ядерно-цитоплазматического соотношения.

После 3-месячного лечения тиотропия бромидом больных ХОБЛ наряду с морфометрическими 
Таблица 1

Морфометрические показатели нейтрофилов индуцированной мокроты в стабильный период ХОБЛ до и после терапии тиотропия бромидом в течение 3 мес. $(M \pm m)$

\begin{tabular}{|c|c|c|c|c|c|}
\hline \multicolumn{2}{|l|}{ Показатель } & \multirow{2}{*}{$\begin{array}{c}1 \text {-я группа } \\
n=21 \\
59,5 \pm 3,4^{*}\end{array}$} & \multirow{2}{*}{$\begin{array}{c}2-я \text { группа } \\
n=28 \\
58,9 \pm 3,6\end{array}$} & \multirow{2}{*}{$\begin{array}{c}\text { 3-я группа } \\
n=22 \\
53,1 \pm 2,1^{*}\end{array}$} & \multirow{2}{*}{$\begin{array}{c}p_{1-2}, 3 ; p_{2-3} \\
>0,05\end{array}$} \\
\hline Площадь клетки, мкм² & до лечения & & & & \\
\hline & после & $68,2 \pm 3,6^{*}$ & $61,6 \pm 3,0$ & $64,6 \pm 2,4^{*}$ & $>0,05$ \\
\hline \multirow[t]{2}{*}{ Площадь цитоплазмы, мкм² } & до лечения & $29,9 \pm 2,0^{* *}$ & $29,3 \pm 1,9^{*}$ & $25,2 \pm 1,7^{* *}$ & $>0,05$ \\
\hline & после & $43,4 \pm 2,5^{\star *}$ & $37,8 \pm 2,1^{*}$ & $41,9 \pm 2,2^{* *}$ & $>0,05$ \\
\hline \multirow[t]{2}{*}{ Площадь ядра, мкм² } & до лечения & $29,6 \pm 2,1$ & $29,6 \pm 2,1$ & $27,9 \pm 1,3$ & $>0,05$ \\
\hline & после & $24,7 \pm 1,9$ & $24,3 \pm 1,8$ & $23,1 \pm 1,3$ & $>0,05$ \\
\hline \multirow{2}{*}{ Ядерно-цитоплазматический индекс } & до лечения & $1,1 \pm 0,1^{*}$ & $1,1 \pm 0,1^{*}$ & $1,2 \pm 0,1^{*}$ & $>0,05$ \\
\hline & после & $0,6 \pm 0,1^{*}$ & $0,7 \pm 0,1^{*}$ & $0,6 \pm 0,1^{*}$ & $>0,05$ \\
\hline
\end{tabular}

изменениями нейтрофилов произошло увеличение содержания миелопероксидазы в цитоплазме этих клеток, о чем свидетельствует снижение показателей оптической плотности цитоплазмы после окрашивания цитохимическими реактивами на МПО. Подобные изменения наблюдались и в отношении катионного протеина - увеличилось внутриклеточное содержание катионных протеинов (табл. 2).

В результате лечения тиотропия бромидом в индуцированной мокроте стал преобладать пул нейтрофилов с высокой внутриклеточной концентрацией МПО и катионных протеинов. В целом можно констатировать тот факт, что после проведенного лечения в бронхолегочном регионе сформировалась среда, свойства которой не инициируют экзоцитоз нейтрофильными лейкоцитами таких цитотоксических субстанций, как миелоперокидаза и катионные протеины.

Ядерно-цитоплазматическое отношение является ключевым фактором, определяющим возможность и активность фагоцитоза бронхолегочными макрофагами. После курса терапии тиотропия бромидом обнаруживалось увеличение размера макрофагов в мокроте во всех группах пациентов $(p<0,05)$. Это объясняется, прежде всего, существенным увеличением площади их цитоплазмы во всех 3 группах (табл. 3).

Исходно макрофаги индуцированной мокроты у всех пациентов не различались по значению ядерно-цитоплазматического отношения $(p>0,05)$. После лечения тиотропия бромидом значение данного показателя уменьшилось во всех группах. Динамика ядерно-цитоплазматического отношения между группами в конце исследования статистически значимо не различалась $(p>0,05)$ (табл. 3$)$.
Таким образом, применение тиотропия бромида в течение 3 мес. позволило существенно изменить качественные характеристики ключевых эффекторных клеток. Исчерпывая вследствие экзоцитоза свой ферментативный запас, нейтрофилы бронхиального дерева не только создают условия для воспалительного ответа в тканях, но и фактически теряют собственную функциональную активность. Увеличение содержания миелопероксидазы и катионного протеина в цитоплазме нейтрофилов, увеличение объема цитоплазмы и размеров самих клеток может свидетельствовать о повышении функциональной активности и жизнеспособности нейтрофилов в связи с уменьшением интенсивности экзоцитоза и преимущественным содержанием цитоферментов внутри клетки [12]. Эти процессы, происходящие на фоне оптимальной и длительной терапии тиотропия бромидом, способствуют стабилизации состояния больного вследствие уменьшения деструктивного потенциала нейтрофилов и снижения интенсивности местного воспаления.

Полноценный дренаж вследствие адекватного расширения бронхов и нормализации качества и реологии мокроты позволяет улучшить санацию бронхиального дерева, следствием чего является снижение бактериальной нагрузки. В результате уменьшается активность нейтрофилов в легких, снижается интенсивность экзоцитоза биологически активных продуктов клетки, тем самым прерывается цепь деструктивных последствий персистирующего воспаления и, возможно, создаются условия для предотвращения дальнейшего прогрессирования болезни.

Таблица 2 Содержание миелопероксидазы и катионного протеина в нейтрофилах индуцированной мокроты больных ХОБЛ до и после терапии тиотропия бромидом $(M \pm m)$

\begin{tabular}{|c|c|c|c|c|c|}
\hline \multicolumn{2}{|c|}{ Показатель, Ед. опт. плотн. } & $\begin{array}{c}1-я \text { группа } \\
n=21\end{array}$ & $\begin{array}{c}2-я \text { группа } \\
n=27\end{array}$ & $\begin{array}{c}\text { 3-я группа } \\
n=27\end{array}$ & $p_{1-2,3} ; p_{2-3}$ \\
\hline \multirow[t]{2}{*}{ Миелопероксидаза } & до лечения & $121,6 \pm 7,4^{\star *}$ & $126,4 \pm 5,1^{* *}$ & $129,9 \pm 6,01^{* *}$ & $>0,05$ \\
\hline & после & $92,3 \pm 5,6^{\star *}$ & $94,23 \pm 6,9^{* *}$ & $84,7 \pm 6,7^{\star \star}$ & $>0,05$ \\
\hline \multicolumn{2}{|c|}{ Динамика активности миелопероксидазы } & $-29,3 \pm 5,7^{* *}$ & $-30,8 \pm 7,2^{* *}$ & $-45,2 \pm 4,1^{\star *}$ & $>0,05$ \\
\hline \multirow[t]{2}{*}{ Катионный протеин } & до лечения & $82,6 \pm 3,5^{\star *}$ & $89,2 \pm 2,7^{* *}$ & $86,3 \pm 4,3^{* *}$ & $>0,05$ \\
\hline & после & $61,2 \pm 2,3^{* *}$ & $71,2 \pm 2,9^{*}$ & $65,7 \pm 3,4^{\star \star}$ & $>0,05$ \\
\hline \multicolumn{2}{|c|}{ Динамика активности катионного протеина } & $-18,7 \pm 1,7^{* *}$ & $-17,9 \pm 3,03^{*}$ & $-20,9 \pm 4,1^{* *}$ & $>0,05$ \\
\hline
\end{tabular}


СПИРИВА॰ продемонстрировапа

долгосрочнов попокительное влияние

на клиническое төчение ХOБЛ, по Аанныи

$4 x$ nemsro rno6anbHoro исеnедования UPLFT"2s :

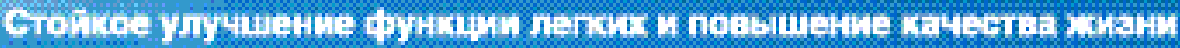

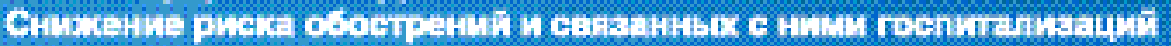

Bnushthe ha cmeprhoct

\section{Назначайте СПИРИВУ९ раньше и помогайте} вашим пациентам сохранить более активный о6раз жизни'2s

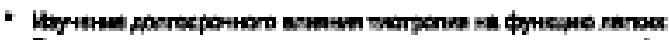

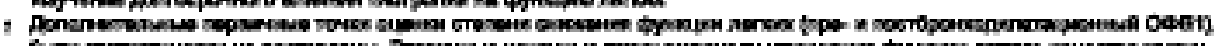

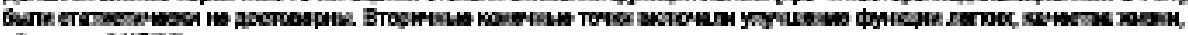

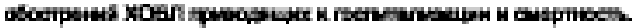

newewastypa:

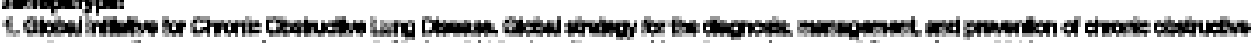

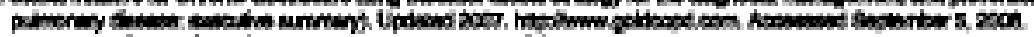

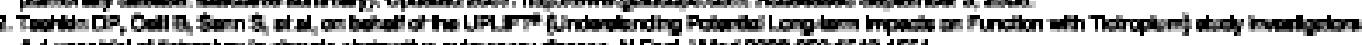

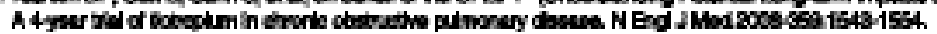

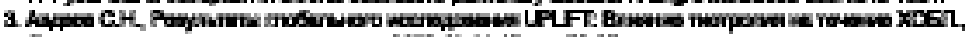

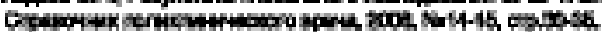

\section{$\boldsymbol{P}$ izer}

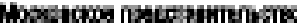

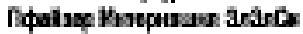

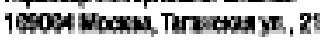

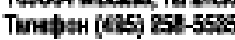

\section{(ii) Boehringer Ingelheim}

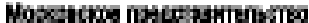

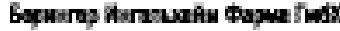

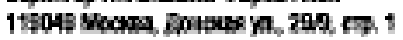
Teropar [eQ6] etsi-root

\section{SPIRIVA*}

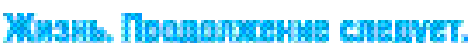

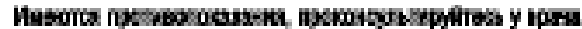

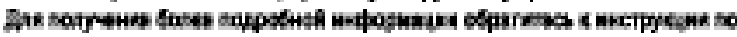

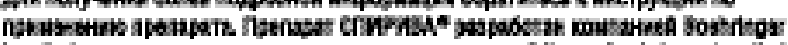

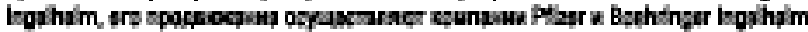

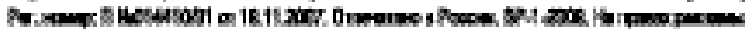


Морфометрические показатели макрофагов индуцированной мокроты в стабильный период ХОБЛ до и после терапии тиотропия бромидом в течение 3 мес. $(M \pm m)$

\begin{tabular}{|c|c|c|}
\hline \multicolumn{2}{|l|}{ Показатель } & \multirow{2}{*}{$\begin{array}{c}\text { 1-я группа } \\
n=21 \\
256,6 \pm 27,8^{* *}\end{array}$} \\
\hline Площадь клетки, мкм² & до лечения & \\
\hline & после & $339,5 \pm 32,9$ ** \\
\hline \multirow[t]{2}{*}{ Площадь цитоплазмы, мкм² } & до лечения & $168,7 \pm 24,3^{* *}$ \\
\hline & после & $263,45 \pm 29,9^{* *}$ \\
\hline \multirow[t]{2}{*}{ Площадь ядра, мкм² } & до лечения & $87,9 \pm 6,04$ \\
\hline & после & $75,45 \pm 4,2$ \\
\hline \multirow[t]{2}{*}{ Ядерно-цитоплазматический индекс } & до лечения & $0,62 \pm 0,04^{* *}$ \\
\hline & после & $0,32 \pm 0,02^{* *}$ \\
\hline
\end{tabular}

Следствием применения тиотропия бромида в течение 3 мес. стало появление в бронхах популяции макрофагов большей величины. Данные изменения важный фактор снижения активности воспаления в дыхательных путях. Снижение активности воспаления в бронхах, с одной стороны, уменьшает приток функционально неспособных к эффективному фагоцитозу моноцитов, с другой - создает условия для созревания и полноценной дифференцировки локального пула макрофагов, что обеспечивает завершенный эффероцитоз клеток (включая нейтрофилы) [13]. Ведь, если макрофаги не способны удалять апоптозные нейтрофилы, последние могут подвергаться вторичному (постапоптотическому) некрозу и высвобождать большое количество нейтрофильных деструктивных протеиназ и оксидантов [14].

Важно отметить, что указанные качественные изменения в индуцированной мокроте на фоне лечения тиотропия бромидом наблюдались во всех группах пациентов с ХОБЛ II-IV стадии независимо от предшествующего лечения.

\section{Заключение}

Назначение тиотропия бромида в качестве длительной поддерживающей терапии при отсутствии противопоказаний патогенетически обоснованно для всех пациентов с клинически значимой ХОБЛ, в т. ч. для больных, получающих лечение фиксированной комбинацией флутиказона пропионат / салметерол.

\section{Литература}

1. Шмелев Е.И. Воспаление - ключевой элемент прогрессирования хронической обструктивной болезни легких. Consilium medicum 2003; 7 (4): 5-7.

2. Barnes P.J. Chronic Obstructive Pulmonary Disease: molecular and cellular mechanisms. Eur. Respir. J. 2003; 22: 672-688.

3. Hogg J.C., Walker B.A. Polymorphonuclear leucocyte traffic in lung inflammation. Thorax 1995; 50: 819-820.

4. Owen C.A., Campbell M.A., Sannes P.L. et al. Cell-surfacebound elastase and cathepsin $\mathrm{G}$ in human neutrophils: a novel non-oxidative mechanism by which neutrophils focus and preserve catalytic activity of serine proteinases. J. Cell Biol. 1995; 131: 775-789.

\begin{tabular}{c|c|c}
$\begin{array}{c}2-я \text { группа } \\
n=28\end{array}$ & $\begin{array}{c}3-я \text { группа } \\
n=22\end{array}$ & $p_{1-2,3} ; p_{2-3}$ \\
$213,9 \pm 13,0^{* *}$ & $265,8 \pm 17,3^{*}$ & $p_{1-2,3}>0,05 ; p_{2-3}=0,03$ \\
$283,9 \pm 18,2^{* *}$ & $338,4 \pm 17,8^{*}$ & $p_{1-2,3}>0,05 ; p_{2-3}=0,026$ \\
$131,1 \pm 9,7^{* *}$ & $166,6 \pm 12,1^{* *}$ & $p_{1-2,3}>0,05 ; p_{2-3}=0,028$ \\
$210,9 \pm 13,9^{* *}$ & $272,1 \pm 13,6^{* *}$ & $p_{1-2,3}>0,05 ; p_{2-3}=0,0029$ \\
$82,8 \pm 4,7^{*}$ & $99,5 \pm 6,2^{* *}$ & $p_{1-2,3}>0,05 ; p_{2-3}=0,015$ \\
$70,2 \pm 4,1^{*}$ & $71,3 \pm 3,4^{* *}$ & $>0,05$ \\
$0,68 \pm 0,04^{* *}$ & $0,65 \pm 0,05^{* *}$ & $>0,05$ \\
$0,34 \pm 0,02^{* *}$ & $0,28 \pm 0,01^{* *}$ & $p_{1-2,3}>0,05 ; p_{2-3}=0,013$
\end{tabular}

5. Чучалин А.Г. Система оксиданты-антиоксиданты и пути медикаментозной коррекции. Пульмонология 2004; 4: 111-115.

6. Barczyk A. Decreased levels of MPO in induced sputum of of patients with chronic obstructive pulmonary disease after treatment with oral glucocorticoids. Chest 2005; 127: 407-415.

7. Peleman R.A., Rytila P.H., Kips J.C. et al. The cellular composition of induced sputum in chronic obstructive pulmonary disease. Eur. Respir. J. 1999; 13: 839-843.

8. Teder P., Vandivier R.W., Jiang D. et al. Resolution of lung inflammation by CD44. Science 2002; 296: 155-158.

9. Kasahara Y., Tuder R.M., Cool C.D. et al. Endothelial cell death and decreased expression of vascular endothelial growth factor and vascular endothelial growth factor receptor 2 in emphysema. Am. J. Respir. Crit. Care Med. 2001; 163: 737-744.

10. Odaka C., Mizuochi T., Yang J. et al. Murine macrophages produce secretory leukocyte protease inhibitor during clearance of apoptotic cells: implications for resolution of the inflammatory response. J. Immunol. 2003; 171: 1507-1514.

11. Liu C.Y. Apoptotic neutrophils undergoing secondary necrosis induce human lung epithelial cell detachment. J. Biomed. Sci. 2003; 10: 746-756.

12. Teder P., Vandivier W.R., Jiang D. et al. Resolution of lung inflammation by CD44. Science 2002; 296 (1): 155-158.

13. Hodge S., Hodge G., Scicchitano R. et al. Alveolar macrophages from subjects with chronic obstructive pulmonary disease are deficient in their ability to phagocytose apoptotic airway epithelial cells. Immunol. Cell Biol. 2003; 8: 289-296.

14. Frankenberger M., Betz R., Weber N. et al. Characterization of a population of small macrophages in induced sputum of patients with chronic obstructive pulmonary disease and healthy volunteers. Clin. Exp. Immunol. 2004; 138 (3): 507-516.

15. Vandivier R.W., Henson P.M., Douglas I.S. Burying the dead. The impact of failed apoptotic cell removal (efferocytosis) on chronic inflammatory lung disease. Chest 2006; 129: $1673-1682$.

\section{Информация об авторах}

Федосенко Сергей Вячеславович - аспирант кафедры госпитальной терапии с курсом физической реабилитации и спортивной медицины; тел.: (3822) 56-06-38; e-mail: s-fedosenko@mail.ru

Черногорюк Георгий Эдинович - д. М. н., проф., зав. кафедрой госпитальной терапии с курсом физической реабилитации и спортивной медицины: тел.: (913)-852-23-36, e-mail: chernogoryuk@yandex.ru Елена Петровна Рослякова - к. м. н., врач-цитолог; тел.: (905) 992-59-75; e-mail: rep-69@sibmail.com 